\title{
Elevated preoperative serum cancer antigen 15.3 levels are associated with reduced disease-free survival: a single-institution experience
}

This article was published in the following Dove Press journal:

Breast Cancer:Targets and Therapy

25 July 2013

Number of times this article has been viewed

\author{
Eyad Fawzi Alsaeed' \\ Huda Abdulkarim² \\ Mutahir A Tunio ${ }^{3}$ \\ 'Radiation Oncology Department, \\ King Khalid University Hospital, King \\ Saud University, Riyadh, Saudi Arabia; \\ 2Department of Medical Oncology, \\ ${ }^{3}$ Department of Radiation Oncology, \\ King Fahad Medical City, Riyadh, \\ Saudi Arabia
}

Background: We aimed to evaluate the prognostic significance of the preoperative tumor-marker cancer antigen (CA) 15.3 in Saudi patients with breast cancer and to find out whether any correlation exists between preoperative CA 15.3 and tumor size and nodal status.

Materials and methods: Preoperative blood samples for serum CA 15.3 levels were taken in 112 breast cancer patients who underwent breast-conserving surgery or modified radical mastectomy between February 1988 and August 2008. Serum levels of CA 15.3 below 35 U/mL were considered normal. The correlation between pre- and postoperative CA 15.3 levels with tumor size and nodal status was calculated using Pearson correlative coefficients. KaplanMeier curves were used to determine disease-free survival (DFS) according to CA 15.3 groups $(<35,36-100$ and above $>100 \mathrm{U} / \mathrm{mL})$.

Results: The mean age of the cohort was 47.0 years (range 23-76, standard deviation 10.3). According to menopausal status, 93 patients $(83.0 \%)$ were premenopausal, and 19 patients (17.0\%) were postmenopausal. Mean preoperative CA 15.3 levels were $43.69 \mathrm{U} / \mathrm{mL}(1.0-209.87)$. Ten-year DFS rates were $100 \%, 84 \%$, and $57.7 \%$ for CA $15.3<35 \mathrm{U} / \mathrm{mL}, 36-100 \mathrm{U} / \mathrm{mL}$, and $>100 \mathrm{U} / \mathrm{mL}$, respectively $(P=0.003)$. Preoperative CA 15.3 levels showed positive correlation with primary tumor size $\left(R=0.43, R^{2}=0.83, P=0.03\right)$ and nodal status $(R=0.59$, $\left.R^{2}=0.28, P<0.0001\right)$, respectively.

Conclusion: Elevated preoperative CA 15.3 above $35 \mathrm{U} / \mathrm{mL}$ in Saudi women breast cancer patients showed correlation with primary tumor size and nodal status, and preoperative CA 15.3 level is an independent prognostic factor for DFS. Preoperative serum CA 15.3 levels may be helpful for risk stratification along with other factors.

Keywords: breast cancer, preoperative serum CA 15.3 levels, correlation, disease-free survival

\section{Introduction}

Breast cancer incidence is increasing globally, and the same is reflected in Saudi Arabia. Breast cancer in Saudi Arabia accounts for $26 \%$ of all newly diagnosed cancers in Saudi women, with an incidence of 21.6 per 100,000, and the majority of those present at a young age and with advanced TNM staging. ${ }^{1,2}$

Serum cancer antigen (CA) 15.3 is a carbohydrate antigen that is secreted from breast cancer cells. It has been the most widely used marker in the last two decades in breast cancer patients for neoadjuvant chemotherapy response and prognosis along with other parameters because of its high sensitivity and specificity. ${ }^{3}$ However, the significance of preoperative CA 15.3 levels is not well known. ${ }^{4} \mathrm{~A}$ few studies have supported an association between high preoperative CA 15.3 and tumor burden (advanced tumor
Correspondence: Mutahir A Tunio Department of Radiation Oncology, King Fahad Medical City, Makkah Al Mukarramah Road, Sulaimaniyah, Riyadh II525, Saudi Arabia

Tel +966 I 2889999

Fax +966 I 2889999

Email drmutahirtonio@hotmail.com 
and nodal status), and others have not. ${ }^{5,6}$ Apart from the prognostic significance for response evaluation, the impact of preoperative CA 15.3 on locoregional control (LRC), distant metastatic control (DMC), and disease-free survival (DFS) is also less studied and its significance not known in Middle Eastern patients with breast cancer. ${ }^{7}$

Our single-institution study aimed to evaluate the prognostic significance of preoperative tumor CA 15.3 in Saudi patients with breast cancer, and also to find out the existence of any correlation of preoperative CA 15.3 with tumor size and nodal status.

\section{Materials and methods}

After receiving approval from the institutional ethical review committee board, we took into this study 112 consecutive patients with breast cancer in whom breast-conserving surgery (BCS) or modified radical mastectomy (MRM) was performed between February 1988 and August 2008 in our hospital. Inclusion criteria were (1) histopathologically confirmed breast cancer, (2) T1-T4, N0-N2, (3) and had undergone BCS or MRM with or without adjuvant hormonal chemotherapy and radiotherapy. Exclusion criteria were (1) presence of distant metastasis, (2) neoadjuvant chemotherapy (as our aim was to see the impact of preoperative CA 15.3 levels in chemotherapy-naïve patients at the time of presentation), and (3) inflammatory or inoperable tumors.

Preoperative serum CA 15.3 levels were determined by enzyme linked immunoassay (BioCheck, Foster City, CA, USA) after taking venous blood samples and centrifugation and processing the serum. Normal levels of serum CA 15.3 were considered normal below or equal to $35 \mathrm{U} / \mathrm{ml}$. According to CA 15.3 levels, patients were grouped into three categories $(<35,36-100$, and $>100 \mathrm{U} / \mathrm{mL})$.

\section{Breast cancer pathological specimens}

After surgery, breast cancer specimens were fixed in $10 \%$ formalin for 12 hours and were examined to evaluate the gross size, histopathological type, grade, presence or absence of lymphovascular invasion, lymph nodes, and retrieved and involved number. Estrogen receptors (ERs), progesterone receptors (PRs), and HER2/neu (human epidermal growth factor receptor 2)-overexpression status underwent immunohistochemical analysis with antibodies against the ERs (Dako, Glostrup, Denmark) and PRs (BioGenex, San Ramon, CA, USA). A cutoff value of $1 \%$ for both receptors was considered ER or PR presence, as per institutional protocol. HER2/neu overexpression was checked for immunohistochemical equivocal cases using a HER2 DNA Probe
Kit (Abbott Laboratories, Abbott Park, IL, USA) according to the instruction manual. HER2/neu was considered positive when the HER2:CEP17 ratio was 2:1 or higher.

\section{Clinical variables}

Additional clinical features, ie, age, menopausal status, associated comorbidities, initial tumor size on physical, mammography and sonography examination, laterality and location of primary tumor, were studied. Surgery was performed using either wide local excision or MRM with axillary lymph-node dissection.

\section{Statistical analysis}

The primary end points were frequency preoperative CA 15.3 levels and correlation with tumor size and lymph-node involvement, impact of preoperative CA 15.3 levels on LRC, DMC, and DFS. The mean, median, and mode of preoperative serum CA 15.3 levels were described. The correlation between preoperative CA 15.3 and tumor size/lymph-node involvement was estimated by Pearson correlative coefficients and the Kruskal-Wallis test. The mean differences and limits of agreement corresponding to the $95 \%$ confidence interval were analyzed.

The times to last follow-up evaluation, appearance of local relapse, and death were calculated from date of starting treatment. DFS was defined as the duration between the entry date and the date of documented disease reappearance, death from cancer, and/or last follow-up (censored). Overall survival was defined as the duration between the entry date and the date of patient death or last follow-up (censored). Probabilities of LRC, DMC, and DFS were determined with the Kaplan-Meier method. The comparisons for various end points were performed using the log-rank test and Cox proportional hazard analysis. All statistical analyses were performed using PASW statistics 18.0 (IBM, Armonk, NY, USA).

\section{Results \\ Clinical characteristics}

Patients' clinical and treatment characteristics are shown in Table 1. The mean age of cohort was 47.0 years (range 23-76, standard deviation 10.3). According to menopausal status, 93 patients $(83.0 \%)$ were premenopausal and 19 patients $(17.0 \%)$ were postmenopausal. Mean body mass index was $31.8 \mathrm{~kg} / \mathrm{m}^{2}$ (range $15.7-52.8$, standard deviation 7.2). A total of 72 patients $(64.3 \%)$ had no comorbidities. Common morbidities in 40 patients $(35.7 \%)$ were hypertension in 14 $(12.5 \%)$, diabetes in nine (8.0\%), and combined hypertension and diabetes in six (5.4\%). Family history was positive in 
Table I Patient characteristics

\begin{tabular}{|c|c|}
\hline Variables & $\mathbf{N}(\%)$ \\
\hline Age & $\begin{array}{l}\text { Mean } 47.0 \text { years } \\
\text { (range } 23-76 \text { ), SD } \pm 10.3\end{array}$ \\
\hline \multicolumn{2}{|l|}{ Age-groups (years) } \\
\hline$<25$ & $2(1.9 \%)$ \\
\hline $25-35$ & $21(18.7 \%)$ \\
\hline $36-45$ & 49 (43.7\%) \\
\hline$>45$ & $40(35.7 \%)$ \\
\hline \multicolumn{2}{|l|}{ Menopausal status } \\
\hline Premenopausal & $93(83 \%)$ \\
\hline Postmenopausal & $19(17 \%)$ \\
\hline \multicolumn{2}{|l|}{ Comorbidities } \\
\hline DM & $9(8.0 \%)$ \\
\hline HTN & $14(12.5 \%)$ \\
\hline $\mathrm{HL}$ & $2(1.8 \%)$ \\
\hline $\mathrm{DM}+\mathrm{HTN}$ & $6(5.4 \%)$ \\
\hline $\mathrm{HL}+\mathrm{DM}+\mathrm{HTN}$ & $9(8.0 \%)$ \\
\hline \multicolumn{2}{|l|}{ Laterality } \\
\hline Unilateral & $108(96.4 \%)$ \\
\hline Bilateral & $4(3.6 \%)$ \\
\hline \multicolumn{2}{|l|}{ Side } \\
\hline Right & $22(20.4 \%)$ \\
\hline Left & $90(79.6 \%)$ \\
\hline \multicolumn{2}{|l|}{ T stage } \\
\hline TI & $28(25.0 \%)$ \\
\hline $\mathrm{T} 2$ & 38 (34.0\%) \\
\hline $\mathrm{T} 3$ & $33(29.5 \%)$ \\
\hline $\mathrm{T} 4$ & $13(11.5 \%)$ \\
\hline \multicolumn{2}{|l|}{$N$ stage } \\
\hline No & $6(5.4 \%)$ \\
\hline $\mathrm{NI}$ & $19(17.0 \%)$ \\
\hline N2 & $40(35.6 \%)$ \\
\hline N3 & 47 (42.0\%) \\
\hline \multicolumn{2}{|l|}{ Histological type } \\
\hline IDC & 95 (84.8\%) \\
\hline ILC & $6(5.4 \%)$ \\
\hline IDC + ILC & $6(5.4 \%)$ \\
\hline Others & 5 (4.4\%) \\
\hline \multicolumn{2}{|l|}{ LVSI } \\
\hline Positive & $42(37.5 \%)$ \\
\hline Negative & 70 (62.5\%) \\
\hline \multicolumn{2}{|l|}{ Receptor status } \\
\hline Luminal A & $34(30.4 \%)$ \\
\hline Luminal B & $31(27.7 \%)$ \\
\hline Basal & II (9.8\%) \\
\hline HER2/neu & $35(32.1 \%)$ \\
\hline \multicolumn{2}{|l|}{ Type of surgery } \\
\hline BCS & $31(28.7 \%)$ \\
\hline MRM & 81 (7I.3\%) \\
\hline \multicolumn{2}{|l|}{ Chemotherapy } \\
\hline Yes & 104 (92.7\%) \\
\hline No & $8(7.3 \%)$ \\
\hline \multicolumn{2}{|l|}{ Radiation therapy } \\
\hline Yes & 89 (79.5\%) \\
\hline No & $23(20.5 \%)$ \\
\hline \multicolumn{2}{|l|}{ Hormonal therapy } \\
\hline Yes & $66(59.0 \%)$ \\
\hline No & $46(41.0 \%)$ \\
\hline
\end{tabular}

Abbreviations: SD, standard deviation; DM, diabetes mellitus; HTN, hypertension; HL, hyperlipidemia; IDC, infiltrating ductal carcinoma; ILC, invasive lobular carcinoma; LVSI, lymphovascular space invasion; BCS, breast-conservation surgery; MRM, modified radical mastectomy; HER2, human epidermal growth factor receptor 2 .
17 patients (15.2\%). The majority of the cohort (57 patients, $79.6 \%)$ had left-side breast cancer and the outer lower quadrant was a common site of tumor location (50 patients, $45.9 \%$ ), followed by the upper outer quadrant (30 patients, 27.5\%). Elevated preoperative CA 15.3 levels were seen in 96 patients $(85.7 \%)$, with a mean value of $43.69 \mathrm{U} / \mathrm{mL}$ (1.0-209.87).

\section{Correlation of preoperative CA 15.3 with tumor size and axillary nodal involvement}

The clinicopathological characteristics according to preoperative CA 15.3-level groups are shown in Table 2. Preoperative serum CA 15.3 levels were correlated with young age, premenopausal status, advanced TNM Classification of Malignant Tumours (TNM) staging, grade 3, and

Table 2 Clinicopathological characteristics according to serum cancer antigen (CA) 15.3 groups

\begin{tabular}{|c|c|c|c|c|}
\hline Variables & $\begin{array}{l}\text { CA } 15.3 \\
<35 \\
(n=16)\end{array}$ & $\begin{array}{l}\text { CA I } 5.3 \\
36-100 \\
(n=30)\end{array}$ & $\begin{array}{l}\text { CA I5.3 } \\
>100 \\
(n=66)\end{array}$ & $P$-value \\
\hline \multicolumn{5}{|l|}{ Age (years) } \\
\hline$<45$ & 7 (43.6\%) & 19 (63.4\%) & $46(69.7 \%)$ & 0.002 \\
\hline$>45$ & $9(56.4 \%)$ & II (36.6\%) & $20(30.3 \%)$ & \\
\hline \multicolumn{5}{|l|}{ Menopausal status } \\
\hline Premenopausal & 12 (75\%) & $23(76.7 \%)$ & $58(87.9 \%)$ & 0.003 \\
\hline Postmenopausal & $4(25 \%)$ & 7 (23.3\%) & $8(12.1 \%)$ & \\
\hline \multicolumn{5}{|l|}{ Tumor size } \\
\hline $\mathrm{TI}$ & 7 (43.6\%) & $8(26.7 \%)$ & $13(19.7 \%)$ & 0.001 \\
\hline $\mathrm{T} 2$ & $7(43.6 \%)$ & $9(30.0 \%)$ & $22(33.3 \%)$ & \\
\hline$\geq \mathrm{T} 3$ & $2(12.8 \%)$ & $13(43.3 \%)$ & $31(47.0 \%)$ & \\
\hline \multicolumn{5}{|l|}{ Nodal status } \\
\hline No & $6(37.5 \%)$ & - & - & 0.001 \\
\hline NI & $4(25.0 \%)$ & 7 (23.3\%) & $8(12.1 \%)$ & \\
\hline N2 & $6(37.5 \%)$ & $10(33.4 \%)$ & $24(36.4 \%)$ & \\
\hline N3 & - & $13(43.3 \%)$ & $34(51.5 \%)$ & \\
\hline \multicolumn{5}{|l|}{ TNM staging } \\
\hline I & $6(37.5 \%)$ & $8(26.7 \%)$ & $8(12.1 \%)$ & 0.001 \\
\hline ॥ & $8(50.0 \%)$ & $9(30.0 \%)$ & $24(36.4 \%)$ & \\
\hline III & $2(12.8 \%)$ & $13(43.3 \%)$ & 34 (5I.5\%) & \\
\hline \multicolumn{5}{|l|}{ Grade } \\
\hline I & $8(50.0 \%)$ & $7(23.3 \%)$ & $6(9.1 \%)$ & 0.02 \\
\hline 2 & 7 (43.6\%) & $12(40.0 \%)$ & $28(42.4 \%)$ & \\
\hline 3 & I (6.4\%) & II (36.7\%) & $32(48.5 \%)$ & \\
\hline \multicolumn{5}{|l|}{ LVSI } \\
\hline Yes & $10(62.5 \%)$ & $12(40.0 \%)$ & $20(30.3 \%)$ & 0.1 \\
\hline No & $6(37.5 \%)$ & $18(60.0 \%)$ & $46(69.7 \%)$ & \\
\hline \multicolumn{5}{|l|}{ Receptor status } \\
\hline Luminal $\mathrm{A}$ & $7(43.6 \%)$ & II (36.7\%) & $17(25.8 \%)$ & 0.0001 \\
\hline Luminal B & 7 (43.6\%) & $9(30.0 \%)$ & 15 (22.7\%) & \\
\hline Basal & - & I (3.3\%) & $10(15.1 \%)$ & \\
\hline HER2/neu & $2(12.8 \%)$ & $9(30.0 \%)$ & 24 (36.4\%) & \\
\hline
\end{tabular}

Abbreviations: LVSI, lymphovascular space invasion; TNM, TNM Classification of Malignant Tumours; HER2, human epidermal growth factor receptor 2. 
receptor status. Elevated CA 15.3 levels were correlated with triple-negative and HER2/neu status. Correlation of CA 15.3 levels with tumor size and nodal involvement are shown in Figures 1 and 2. Elevated preoperative CA 15.3 levels were positively correlated with primary tumor size $\left(R=0.43, R^{2}=0.83, P=0.03\right)$ and nodal status $(R=0.59$, $\left.R^{2}=0.28, P<0.0001\right)$.

\section{Locoregional recurrence, distant control, and overall survival}

Ten locoregional recurrences (LRRs; 8.93\%) were seen among 112 breast cancer patients. Four (40\%) LRRs occurred at the scar site, and six LRRs (60\%) were seen in the ipsilateral axilla and supraclavicular regions. The median time of LRR was 3.6 years (range 2.73-5.1). The 10-year actual LRC rate was $86.4 \%$. Distant metastases were documented in 29 patients at 10 years, with 10 actual DMC rates averaging 63\% (95\% confidence interval 57\%-79.0\%). Ten-year
DFS rates were $100 \%, 84 \%, 57.7 \%$ in CA $15.3<35 \mathrm{U} / \mathrm{mL}$, 36-100 U/mL, and $>100 \mathrm{U} / \mathrm{mL}$, respectively $(P=0.003)$. In preoperative CA 15.3 groups, there was no difference between LRRs; however, CA 15.3 above $35 \mathrm{U} / \mathrm{mL}$ had worse DMC and DFS rates (Figure 3).

Cox proportional analysis of clinical and histopathological prognostic factors in our cohort showed four prognostic factors influencing the LRRs: (1) age less than 45 years, (2) premenopausal status, (3) presence of lymphovascular invasion, and (4) no adjuvant radiotherapy (Table 3). For DMC, in addition to age less than 45 years, premenopausal status, and breast cancer subtypes, elevated preoperative CA 15.3 levels were found to be an independent prognostic factor (Tables 4 and 5).

\section{Discussion}

Correlation of preoperative serum CA 15.3 levels with primary tumor size and nodal status and its prognostic significance on

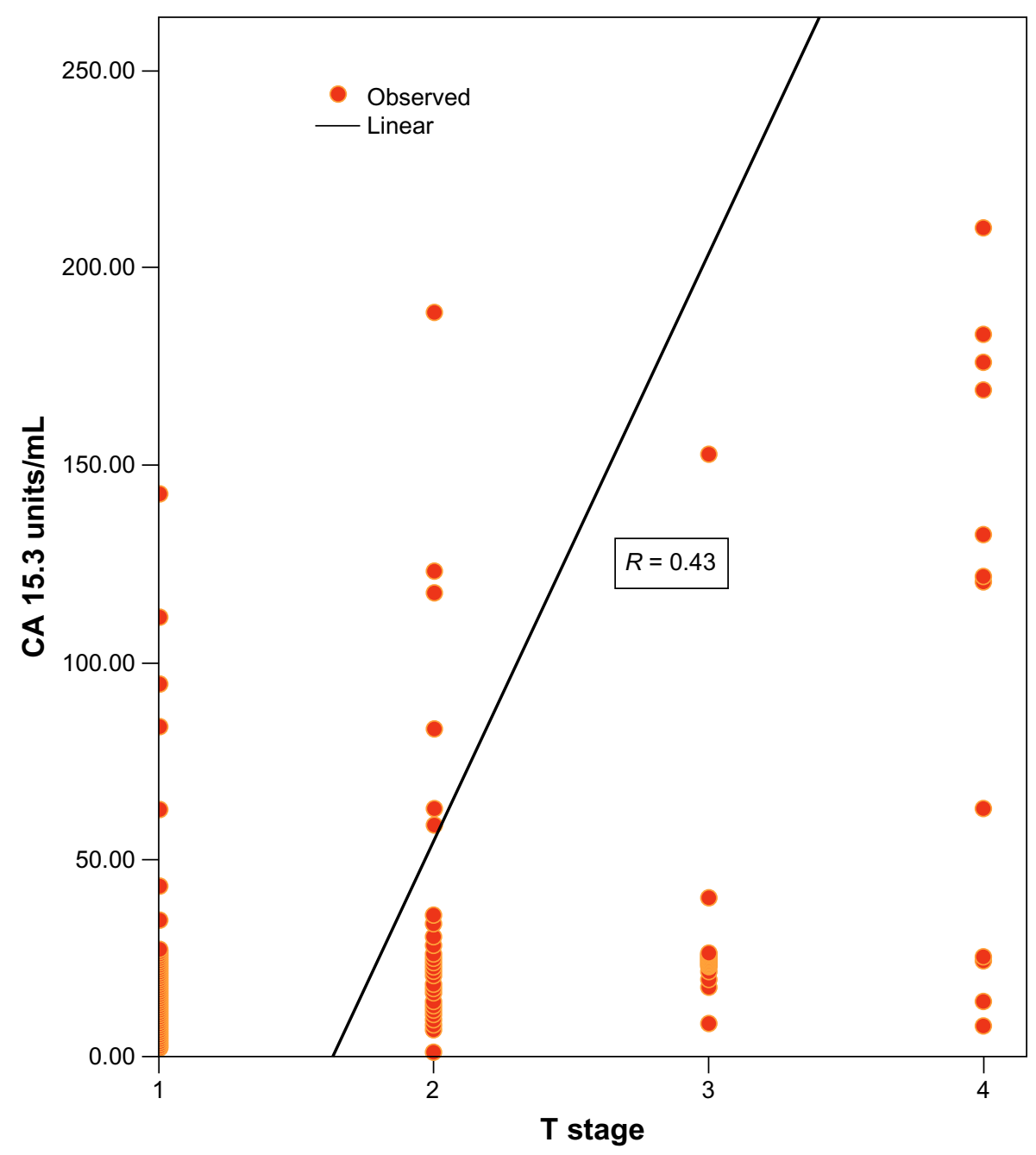

Figure I Correlation between preoperative serum cancer antigen (CA) I5.3 levels and postoperative primary tumor (T) stage. 


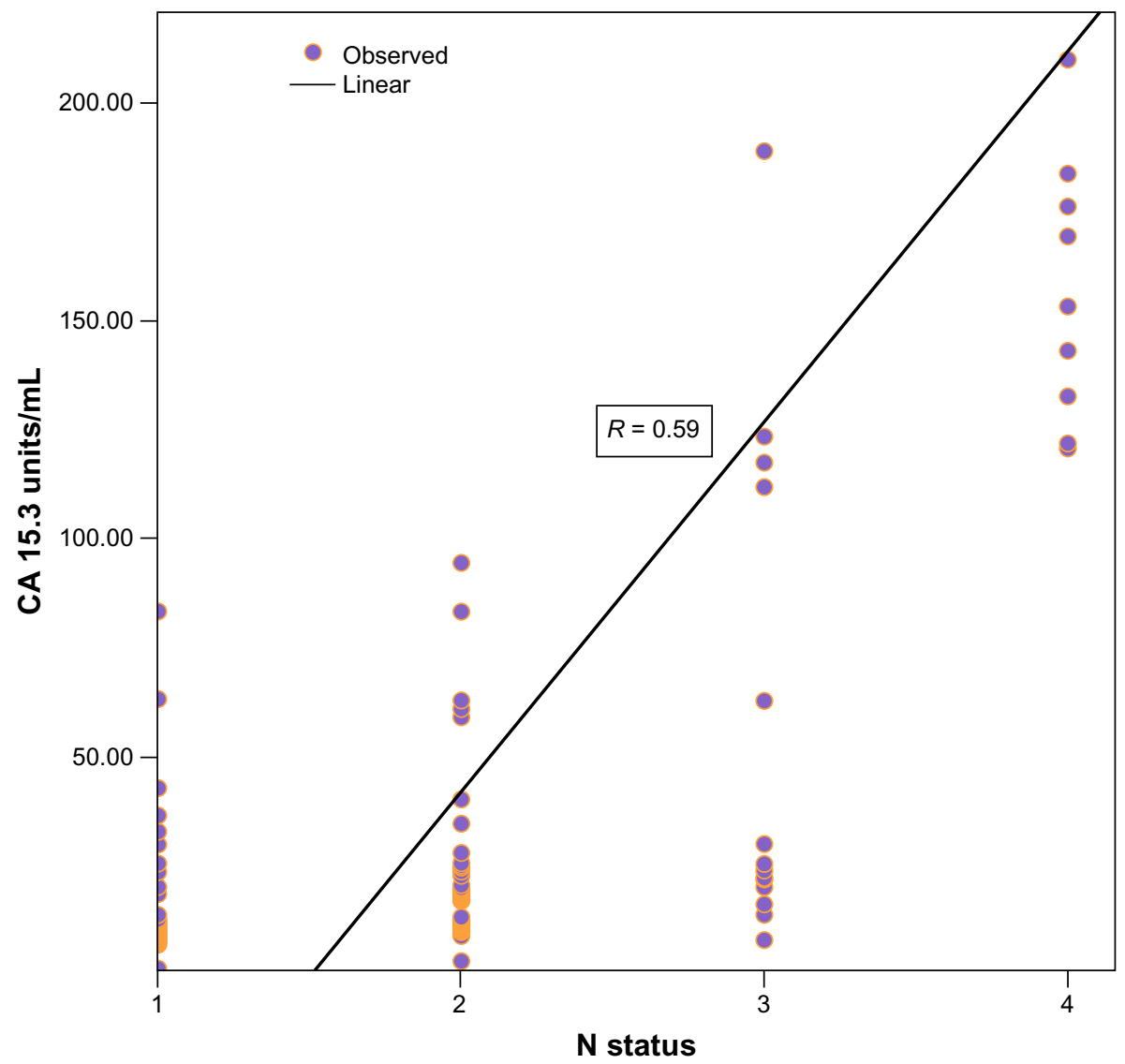

Figure 2 Correlation between preoperative serum cancer antigen (CA) 15.3 levels and postoperative axillary nodal $(\mathrm{N})$ status.

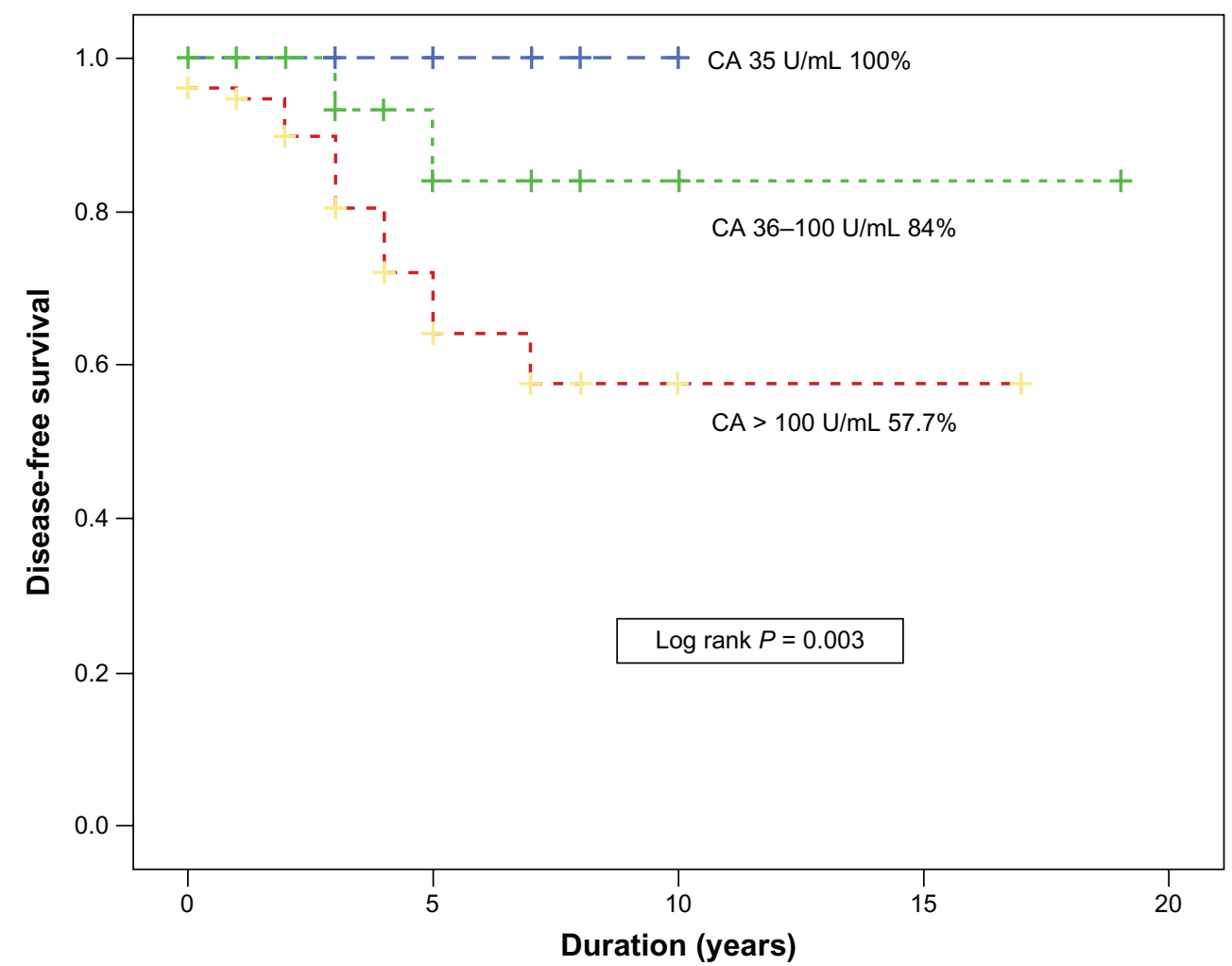

Figure 3 Disease-free survival according to cancer antigen (CA) 15.3-level groups. 
Table 3 Cox regression (multivariate) analysis of prognostic factors for locoregional recurrence in breast cancer

\begin{tabular}{llll}
\hline Variables & $\begin{array}{l}\text { Hazard } \\
\text { ratio }\end{array}$ & $\begin{array}{l}\text { Confidence } \\
\text { interval }\end{array}$ & P-value \\
\hline Age, years, $<45$ vs $>45$ & 2.7 & $2.2-3.1$ & 0.02 \\
Premenopausal vs & 2.4 & $1.9-2.9$ & 0.03 \\
postmenopausal & & & \\
Luminal A vs luminal B & 1.2 & $0.9-1.3$ & 0.05 \\
Luminal A vs other subtypes & 1.1 & $0.8-1.2$ & 0.4 \\
$<$ T3 vs T4 & 2.2 & $1.7-3.2$ & 0.01 \\
NI vs N2 & 2.8 & $2.1-3.9$ & 0.001 \\
$<$ G3 vs $>$ G3 & 1.1 & $0.8-1.2$ & 0.5 \\
LVSI vs LVSI & 1.7 & $1.2-2.3$ & 0.02 \\
Adjuvant RT vs no RT & 3.8 & $2.7-4.2$ & 0.001 \\
Adjuvant CT vs no CT & 1.1 & $0.7-1.2$ & 0.5 \\
Adjuvant HT vs no HT & 1.1 & $0.7-1.2$ & 0.5 \\
\hline Abbrevat
\end{tabular}

Abbreviations: LVSI, lymphovascular space invasion; RT, radiation therapy; $C T$, chemotherapy; HT, hormonal therapy; vs, versus.

DMC and DFS in patients with breast cancer has been demonstrated in Western data ${ }^{5,8}$; however, the impact of preoperative CA 15.3 levels in Middle Eastern women with breast cancer has not been well studied. ${ }^{8-10}$ In our region, women with breast cancer present at a young age, mostly premenopausal, and with advanced TNM stage and high HER2/neu expression (32.2\%), which are well-known prognostic factors for tumor and nodal stage in breast cancer. Similar findings were seen in our small cohort, and we confirmed the correlation of elevated preoperative CA 15.3 with young age, premenopausal status, advanced TNM staging, histological grade, and basal and HER2/neu-type receptors, and also confirmed preoperative CA 15.3 levels as independent prognostic factors for DMC and DFS, similar to Western data. ${ }^{11,12}$

Table 4 Cox regression (multivariate) analysis of prognostic factors for distant metastasis in breast cancer

\begin{tabular}{llll}
\hline Variables & $\begin{array}{l}\text { Hazard } \\
\text { ratio }\end{array}$ & $\begin{array}{l}\text { Confidence } \\
\text { interval }\end{array}$ & P-value \\
\hline Age, years, $<45$ vs $>45$ & 2.6 & $2.1-3.0$ & 0.02 \\
Premenopausal vs & 1.4 & $1.2-1.9$ & 0.04 \\
postmenopausal & & & \\
Luminal A vs luminal B & 5.2 & $3.7-7.3$ & 0.000 I \\
Luminal A vs other subtypes & 4.7 & $3.6-7.2$ & 0.000 I \\
$<$ T3 vs T4 & 2.0 & $1.5-2.5$ & 0.01 \\
NI vs N2 & 3.9 & $2.6-4.2$ & 0.001 \\
$<$ G3 vs $>$ G3 & 1.1 & $0.8-1.2$ & 0.5 \\
LVSI ${ }^{+}$vs LVSI & 3.8 & $2.5-4.1$ & 0.001 \\
Adjuvant RT vs no RT & 1.1 & $0.8-1.2$ & 0.5 \\
Adjuvant CT vs no CT & 1.2 & $1.0-1.3$ & 0.3 \\
Adjuvant HT vs no HT & 5.2 & $4.7-8.2$ & 0.000 I \\
Age, years, $<45$ vs $>45$ & 3.1 & $2.6-5.2$ & 0.001 \\
\hline
\end{tabular}

Abbreviations: LVSI, lymphovascular space invasion; RT, radiation therapy; CT, chemotherapy; $\mathrm{HT}$, hormonal therapy; vs, versus.
Table 5 Cox regression (multivariate) analysis of prognostic factors for disease-free survival in breast cancer

\begin{tabular}{llll}
\hline Variables & $\begin{array}{l}\text { Hazard } \\
\text { ratio }\end{array}$ & $\begin{array}{l}\text { Confidence } \\
\text { interval }\end{array}$ & P-value \\
\hline Age, years, $<45$ vs $>45$ & 2.5 & $2.0-2.9$ & 0.02 \\
Premenopausal vs & 1.4 & $1.2-1.9$ & 0.04 \\
postmenopausal & & & \\
Luminal A vs luminal B & 4.3 & $3.6-6.2$ & 0.001 \\
Luminal A vs other subtypes & 5.7 & $4.5-8.2$ & 0.000 I \\
$<$ T3 vs T4 & 2.0 & $1.5-2.5$ & 0.01 \\
NI vs N2 & 2.9 & $2.5-3.5$ & 0.002 \\
$<$ G3 vs $>$ G3 & 1.1 & $0.8-1.2$ & 0.5 \\
LVSI vs LVSI & 1.1 & $0.8-1.2$ & 0.5 \\
Adjuvant RT vs no RT & 2.7 & $2.4-2.9$ & 0.002 \\
Adjuvant CT vs no CT & 1.1 & $0.9-1.2$ & 0.3 \\
Adjuvant HT vs no HT & 3.5 & $3.0-5.2$ & 0.000 I \\
Age, years, $<45$ vs $>45$ & 2.1 & $1.8-3.3$ & 0.002 \\
\hline Abbrevitis
\end{tabular}

Abbreviations: LVSI, lymphovascular space invasion; RT, radiation therapy; $C T$, chemotherapy; $\mathrm{HT}$, hormonal therapy; vs, versus.

Potential strengths of our study were complete data of preoperative serum CA 15.3 in all patients and a long follow-up period, and possible limitations of our study were that (1) we did not take postoperative blood samples for serum CA 15.3 levels, (2) ours was a small cohort, and (3) patients receiving neoadjuvant chemotherapy were excluded, as our aim was to see the impact of preoperative CA 15.3 on DFS in neoadjuvant chemotherapy-naïve patients. Bottini et al have reported that serum CA 15.3 levels did not substantially change after neoadjuvant chemotherapy, despite the high response rate obtained after surgery. ${ }^{13}$

In conclusion, our data in patients with breast cancer suggest that elevated preoperative CA15.3 levels are associated with advanced TNM staging, histological grade, and basal and HER2/neu-receptor status, and thus a high risk of recurrence locally or at distant sites. We found preoperative CA 15.3 level an independent prognostic factor for DFS. Although the American Society of Clinical Oncology panel does not recommend therapeutic decisions be based on preoperative serum CA 15.3, we recommend the incorporation of routine preoperative CA 15.3 levels in our patients based on the aforementioned studies, and such patients with elevated preoperative serum CA 15.3 levels may benefit from aggressive treatment. However, larger prospective trials are required to predict the significance of preoperative serum CA 15.3 levels on LRC, DMC, and DFS in breast cancer patients.

\section{Disclosure}

The authors report no conflicts of interest in this work. 


\section{References}

1. Saudi Arabia Cancer Incidence and Survival Report 2007 [webpage on the Internet]. Saudi Arabia: Saudi Cancer Registry; 2007. Available from: http://ghdx.healthmetricsandevaluation.org/record/saudi-arabia-cancerincidence-and-survival-report-2007. Accessed July 2, 2013.

2. Ibrahim EM, Zeeneldin AA, Sadiq BB, Ezzat AA. The present and the future of breast cancer burden in the Kingdom of Saudi Arabia. Med Oncol. 2008;25:387-393.

3. Miya T, Watanabe T, Adachi I, et al. Analysis of cytosol CA15-13, carcinoembryonic antigen, and estrogen and progesterone receptors in breast cancer tissues. Jpn J Cancer Res. 1992;83:171-177.

4. Duffy MJ, Catherine D, Rachel K, et al. High preoperative CA 15.3 concentrations predict adverse outcome in node-negative and node-positive breast cancer: study of 600 patients with histologically confirmed breast cancer. Clin Chem. 2004;50:559-563.

5. Sandri MT, Salvatici M, Botteri E, et al. Prognostic role of CA15.3 in 7942 patients with operable breast cancer. Breast Cancer Res Treat. 2012;132:317-326.

6. Lumachi F, Brandes AA, Ermani M, Bruno G, Boccagni P. Sensitivity of serum tumor markers CEA and CA 15-13 in breast cancer recurrences and correlation with different prognostic factors. Anticancer Res. 2000;20:4751-4755.

7. Günczler P, Ogris E, Maca S, Danmayr E. Tumor markers in breast cancer: on the diagnostic value of serum determinations in clinical freedom from tumor and manifest disease. Onkologie. 1989;12:209-214. German.
8. Molina R, Augé JM, Escudero JM, et al. Evaluation of tumor markers (HER-2/neu oncoprotein, CEA and CA 15.3) in patients with locoregional breast cancer: prognostic value. Tumour Biol. 2010;31: 171-180.

9. Bahrami A, Mortazavizadeh MR, Yazdi MF, Chamani M. Serial tumour markers serum carcinoembryonic antigen and cancer antigen 15-13 assays in detecting symptomatic metastasis in breast cancer patients. East Mediterr Health J. 2012;18:1055-1059.

10. Elfagieh M, Abdalla F, Gliwan A, Boder J, Nichols W, Buhmeida A. Serum tumour markers as a diagnostic and prognostic tool in Libyan breast cancer. Tumour Biol. 2012;33:2371-2377.

11. Morcos NY, Zakhary NI, Said MM, Tadros MM. Postoperative simple biochemical markers for prediction of bone metastases in Egyptian breast cancer patients. Ecancermedicalscience. 2013;7:305.

12. Khatcheressian JL, Hurley P, Bantug E, et al. Breast cancer followup and management after primary treatment: American Society of Clinical Oncology clinical practice guideline update. J Clin Oncol. 2013;31:961-965

13. Bottini A, Berruti A, Tampellini M, et al. Influence of neoadjuvant chemotherapy on serum tumor markers CA 15-13, MCA, CEA, TPS and TPA in breast cancer patients with operable disease. Tumor Biol. 1997;18:301-310.
Breast Cancer: Targets and Therapy

\section{Publish your work in this journal}

Breast Cancer: Targets and Therapy is an international, peerreviewed open access journal focusing on breast cancer research, identification of therapeutic targets and the optimal use of preventative and integrated treatment interventions to achieve improved outcomes, enhanced survival and quality of life for the cancer patient.

\section{Dovepress}

View the full aims and scopes of this journal here. The manuscript management system is completely online and includes a very quick and fair peer-review system, which is all easy to use. Visit http:// www.dovepress.com/testimonials.php to read real quotes from published authors. 